\title{
Regime shifts in annual maximum rainfall across Australia - implications for intensity-frequency-duration (IFD) relationships
}

\author{
D. C. Verdon-Kidd and A. S. Kiem \\ Environmental and Climate Change Research Group, School of Environmental and Life Sciences, University of Newcastle, \\ Callaghan, Australia
}

Correspondence to: D. C. Verdon-Kidd (danielle.verdon@ newcastle.edu.au)

Received: 3 March 2015 - Published in Hydrol. Earth Syst. Sci. Discuss.: 30 March 2015

Revised: 4 November 2015 - Accepted: 5 November 2015 - Published: 3 December 2015

\begin{abstract}
Rainfall intensity-frequency-duration (IFD) relationships are commonly required for the design and planning of water supply and management systems around the world. Currently, IFD information is based on the "stationary climate assumption" that weather at any point in time will vary randomly and that the underlying climate statistics (including both averages and extremes) will remain constant irrespective of the period of record. However, the validity of this assumption has been questioned over the last 15 years, particularly in Australia, following an improved understanding of the significant impact of climate variability and change occurring on interannual to multidecadal timescales. This paper provides evidence of regime shifts in annual maximum rainfall time series (between 1913-2010) using 96 daily rainfall stations and 66 sub-daily rainfall stations across Australia. Furthermore, the effect of these regime shifts on the resulting IFD estimates are explored for three long-term (19132010) sub-daily rainfall records (Brisbane, Sydney, and Melbourne) utilizing insights into multidecadal climate variability. It is demonstrated that IFD relationships may under- or over-estimate the design rainfall depending on the length and time period spanned by the rainfall data used to develop the IFD information. It is recommended that regime shifts in annual maximum rainfall be explicitly considered and appropriately treated in the ongoing revisions of the Engineers Australia guide to estimating and utilizing IFD information, Australian Rainfall and Runoff (ARR), and that clear guidance needs to be provided on how to deal with the issue of regime shifts in extreme events (irrespective of whether this is due to natural or anthropogenic climate change). The findings of our study also have important implications for other regions of the world that exhibit considerable hydroclimatic
\end{abstract}

variability and where IFD information is based on relatively short data sets.

\section{Introduction}

Information on rainfall event intensity, frequency, and duration (IFD or IDF as it is known in some countries) plays a critical role in the design of dams, bridges, storm water drainage systems, and floodplain management. Dependent upon the application, information is required for event durations ranging from hours to several days. The development of IFD relationships were first proposed by Bernard (1932) and since then different versions of this relationship have been developed and applied worldwide (e.g. Bara et al., 2009; Chen, 1983; Hershfield, 1961; IHP-VII, 2008; Nhat et al., 2006; Raiford et al., 2007).

Historically, in Australia, IFD design rainfall curves were developed by the Australian Bureau of Meteorology (BoM) for durations ranging from $5 \mathrm{~min}$ to $72 \mathrm{~h}$ and average return intervals (ARIs) of 1-100 years (however, recently additional durations and ARIs have also been developed). Up until very recently, the IFD information available to (and used by) engineers and hydrologists was developed almost 30 years ago, as part of the Engineers Australia publication Australian Rainfall and Runoff (ARR in 1987. New IFD information was released early in 2013 after a major revision of IFD information carried out by Engineers Australia. Importantly, the revised IFD information is based on a longer and more extensive rainfall data set (http://www.bom.gov. au/water/designRainfalls/ifd/). However, the BoM and Engineers Australia still recommend to use the ARR 1987 in- 
formation for existing flood studies, the probabilistic rational method, and to conduct sensitivity testing with the revised 2013 ARR parameters including the new IFD design rainfalls (http://www.bom.gov.au/water/designRainfalls/ifd/ index.shtml).

At the time of writing, the revised IFD information does not take into account the impact of climate change on IFD estimates. This is part of ongoing research commissioned through Engineers Australia. It is also not yet clear how or if the role of natural climate variability is going to be considered. Of concern is the fact that, currently, estimates of IFD are based on the assumption that a "climatic trend, if it exists in a region, has negligible effect on the design intensities" (Pilgrim, 1987). This is known as the stationary climate assumption (i.e. the statistical properties of the rainfall do not change over time) and implies that the chance of an extreme event occurring is the same at any point in time (past or future). However, the validity of this assumption has been questioned over the last 15 years following the demonstration of the significant impact of climate variability occurring on interannual to multidecadal timescales in Australia. For example, research has shown that annual maximum flood risk estimates in Australia vary depending on climate state (e.g. Ishak et al., 2013; Kiem et al., 2003; Leonard et al., 2008). Importantly these studies demonstrate that basing flood risk estimates on an unsuitable time period has the potential to significantly underestimate (or overestimate) the true risks. This may apply to the design rainfall given that current IFD estimates are based on varying lengths of data spanning different time periods (the latest IFD estimates are based on all daily read stations with 30 or more years of record and all continuously recording stations with more than 8 years of record).

Khaliq et al. (2006) explained that the traditional idea of probability of exceedance and return period are no longer valid under non-stationarity. Recently, Jakob et al. (2011a) found that rainfall quantile estimates derived for Sydney Observatory Hill for the period 1976-2005 show significant decreases across durations from $6 \mathrm{~min}$ to $72 \mathrm{~h}$. Jakob et al. (2011b) subsequently extended the sub-daily rainfall data analysis to 31 sites located in southeastern Australia, assessing variations in frequency and magnitude of intense rainfall events across durations from $6 \mathrm{~min}$ to $72 \mathrm{~h}$. This study identified two different trends in the data sets: a decreasing trend in frequency of events at durations of $1 \mathrm{~h}$ and longer for sites in the north of the study region, while sites in the southern cluster displayed an increase in frequency of events, particularly for sub-hourly durations. Importantly, Jakob (2011a, b) concluded that, for at least some regions of Australia, trends found in historical records have the potential to significantly affect design rainfall estimates. Westra and Sisson (2011) also investigated evidence of trends in extreme precipitation at sub-daily and daily timescales (1965-2005) using a spatial extreme value model. They identified a statistically significant increasing trend in precipi- tation extremes for the sub-daily data set; however, at the daily timescale no change in annual maximum rainfall could be detected with the exception of the southwest of Western Australia (Westra and Sisson, 2011). Furthermore, Yilmaz and Perera (2014) conducted change point analysis for extreme rainfall data for storm durations ranging from $6 \mathrm{~min}$ to $72 \mathrm{~h}$ in Melbourne and found evidence of regime shifts, concluding that the year 1966 is a statistically significant change point. Yilmaz et al. (2014) then investigated changes in extreme rainfall through trend analysis, non-stationarity tests, and non-stationary GPD (Generalized Pareto Distribution) (NSGPD) models for Melbourne. They found statistically significant extreme rainfall trends for storm durations of $30 \mathrm{~min}, 3$, and $48 \mathrm{~h}$; however, for above storm durations there was no evidence of a regime shift (which they termed "non-stationarity") according to statistical non-stationarity tests and non-stationary GPD (Yilmaz et al., 2014).

A limitation of the analysis presented by Westra and Sisson (2011) and Jakob et al. (2011a, b) is that they tested for linear trends in the rainfall data series based on the hypothesis that extreme rainfall events would have either decreased, increased, or exhibited no trend over the time period being investigated. However, these are not the only attributes of trend detection, since annual rainfall maxima may also cycle through interannual to multidecadal periods (note that Westra and Sisson (2011) also investigated possible links between extreme rainfall and annual fluctuations during El Niño-Southern Oscillation - ENSO). Therefore, depending on what time period the annual rainfall maxima data are derived from (in reference to any long-term cycles or epochs), the observed trends may be misleading or even not apparent (leading to the misconception that regime shifts are nonsignificant or not an important consideration). Recently, Yilmaz et al. (2014) investigated the potential impact of the Interdecadal Pacific Oscillation (IPO) on extreme rainfall and resulting IFD for a case study in Melbourne. They concluded that the negative IPO phase can be the driver of higher rainfall intensities for long durations and high return periods. However, the trends in extreme rainfall data and differences in rainfall intensities for short storm durations and return periods could not be explained with the IPO influence. Given that Melbourne is located in southeastern Australia, where the influence of the IPO is temporally variable due to other climate drivers operating (acting to enhance or suppress impacts, see Kiem and Verdon-Kidd, 2009, 2010), the research by Yilmaz et al. (2014) provides promise for developing relationships between extreme rainfall and the IPO for regions where the IPO may have a more consistent influence (due to fewer competing climate modes), such as in northeastern Australia.Therefore, this paper aims to establish if there is evidence of regime shifts in the annual maximum rainfall time series ( $1 \mathrm{~h}-7$ days) across Australia by testing for shifts (regardless of direction or timing) in the long-term sub-daily and daily data. Furthermore, the implications on IFD estimation are explored, along with the potential influence of 


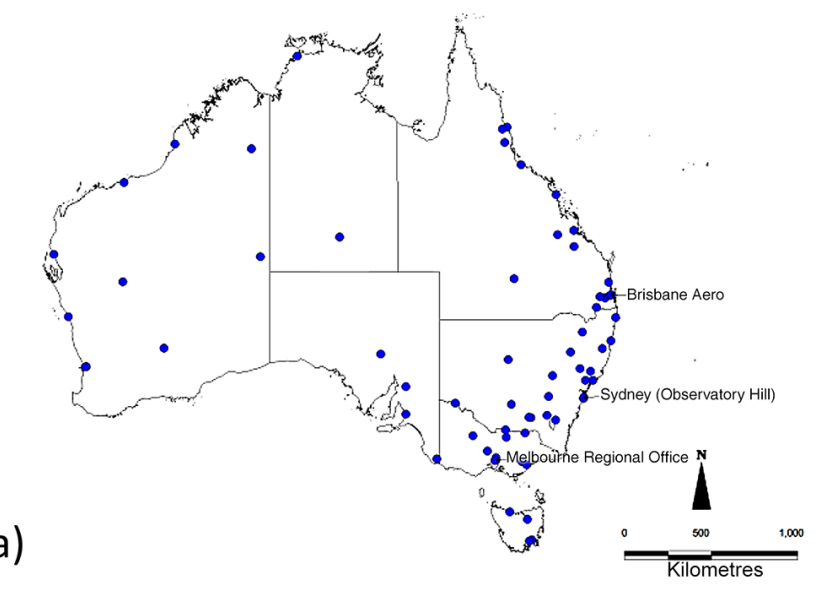

(b)

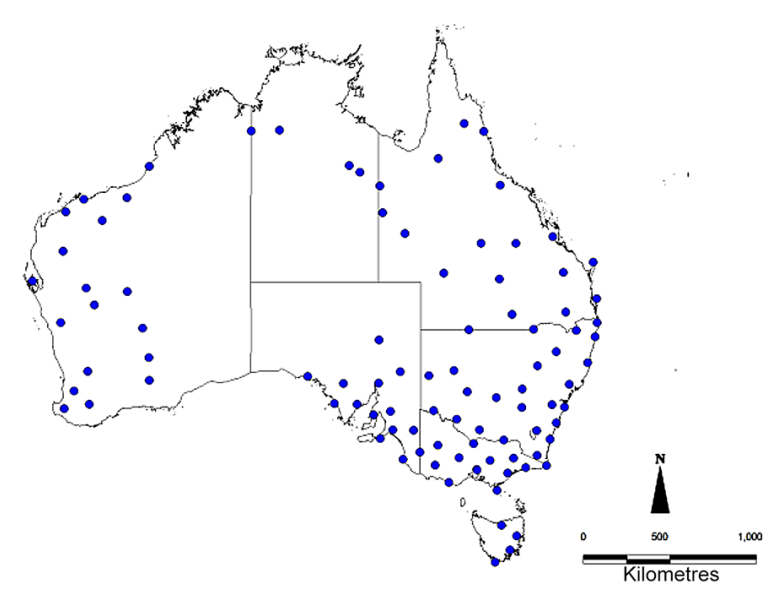

Figure 1. (a) Reference stations for sub-daily rainfall, (b) Reference stations for daily rainfall. Note the three long-term sub-daily stations used in the IFD analysis are also labelled.

the IPO on extreme rainfall and resulting IFD. Recommendations are then provided as to how these insights may be incorporated in future revisions of $A R R$.

\section{Data and methods}

\subsection{Data}

\subsubsection{Rainfall data}

Sub-daily and daily rainfall data for Australia were obtained from the BoM. Sub-daily data records from continuously recording (i.e. pluviograph) rainfall stations in Australia tend to be relatively short, hindering the ability to conduct trend and attribution studies. In this study, pluviograph rainfall stations were chosen with data spanning at least 40 years and at least $90 \%$ complete, resulting in 66 stations (see Fig. 1a). In order to address the concerns raised in the Introduction about short-term data analysis (note that according to Raiford et al. (2007) ARIs should not be extrapolated from more than twice the record length), three long-term data sets, highlighted in Fig. 1a, were chosen for further analysis that contained sub-daily rainfall data from at least 1913-2010 (Brisbane Aero, Sydney (Observatory Hill), and Melbourne Regional Office).

Daily rainfall stations with data spanning the period 19002009 were selected in order to capture as much temporal variability as possible (see Fig. 1b). These stations were filtered according to the amount of data missing in order to identify the highest quality stations recording rainfall during this period, resulting in 96 being considered suitable for further analysis. Due to variability in the quality and quantity of rainfall data in each state of Australia, the following selection criteria were applied:

- New South Wales, Queensland, and Victoria - selected stations are at least $97 \%$ complete;
- Tasmania - selected stations are at least $90 \%$ complete; and

- southern Australia, Northern Territory, and Western Australia - selected stations are at least $85 \%$ complete.

\subsubsection{Climate index data}

The climate of Australia has experienced a number of regime shifts in climate during its history, resulting in sustained periods of above average rainfall and storminess and abnormally cool temperatures, followed by the reverse conditions (i.e. droughts and elevated bushfire risk) (e.g. Erskine and Warner 1988; Franks and Kuczera, 2002; Kiem et al., 2003; Kiem and Franks, 2004; Verdon et al., 2004). These shifts have tended to occur every 20-30 years and are associated with changes in the IPO (Power et al., 1999). The IPO represents variable epochs of warming (i.e. positive phase) and cooling (i.e. negative phase) in both hemispheres of the Pacific Ocean (Folland et al., 2002). Importantly, the IPO has been shown to influence the magnitude and frequency of flood and drought cycles across eastern Australia (Kiem et al., 2003; Kiem and Franks, 2004). In New Zealand, the IPO is also associated with similar shifts in flood frequency (McKerchar and Henderson, 2003). It has been noted that, following the abrupt shift in the IPO in the mid 1970s, the period, amplitude, spatial structure, and temporal evolution of ENSO markedly changed (Wang and An, 2001)istorically, during negative phases of the IPO there tends to be more La Niña (wet) events and fewer El Niño (dry) events (Kiem et al., 2003; Verdon and Franks, 2006), resulting in an overall "wet" epoch for eastern Australia and New Zealand. While during the positive phase of the IPO there tends to be a higher frequency of El Niño events and fewer La Niña events (Kiem et al., 2003; Verdon and Franks, 2006), resulting in an overall "dry" epoch. In this study negative phases of the IPO were 
defined as 1913-1920 and 1945-1977, while positive phases included 1921-1944 and 1978-2010.

\subsection{Statistical tests}

A 20-year moving window was used to test for low frequency variability in the annual maxima time series $(1 \mathrm{~h}, 1$-day, and 7-day). A Mann-Whitney $U$ test was then used to determine the statistical significance of possible regime shifts by testing if the first 10 years of data were significantly different from the second 10 years, within the 20-year window (the null hypothesis in this case was that the data was independently distributed). If the difference in medians was found to be statistically significant (i.e. $p$ value $<0.05$ ) and there was a change in sign of the median values (e.g. switch from negative to positive), a climate shift was postulated to have occurred during the 10th year of the window. The MannWhitney $U$ test is a robust test that does not place implicit assumptions on the underlying distribution of the data (i.e. it is a distribution-free test), which is particularly appropriate here due to the small number of years used in each window (Kundzewicz and Robson, 2004). Note that a number of different size windows were also tested; however, this did not change the results or conclusions.

A second test was also applied to identify step changes in the 1-day and 7-day annual maxima time series known as the distribution-free CUSUM (cumulative sum) with resampling (note that the test was not applied to the shorter sub-daily data as longer data sets are recommended for this method). CUSUM tests whether the means in two parts of a record are different (for an unknown time of change). The second test was applied as it does not require the use of a moving window (which is a limitation of the Mann-Whitney $U$ test described above). However the CUSUM test sequentially splits the time series into two portions (which are not necessarily equal), which may be a problem if more than one cycle/shift is present in the time series.

The existence of serial correlation (or autocorrelation) in a time series will affect the ability of tests (such as the MannWhitney $U$ and CUSUM) to assess the site significance of a trend (e.g. Yu et al., 2003; Serinaldi and Kilsby, 2015b). The presence of cross-correlation among sites in a network will also influence the ability of the test to evaluate the field significance of trends over the network (e.g. Yu et al., 2003; Douglas et al., 2000; Guerreiro et al., 2014). Therefore, prior to applying the change point analysis as described above, the Durbin-Watson (DW) statistic was used to test for autocorrelation in the annual maxima time series (Durbin and Watson, 1950, 1951). In this case the null hypothesis is that the residuals from an ordinary least-squares regression are not autocorrelated against the alternative that the residuals follow an ARI process. All DW statistic values were found to be greater than 1.562 (the upper bound for $1 \%$ significance and a sample size of $\sim 100$ ), providing no evidence to reject the null hypothesis. Therefore, any regime shifts detected using the change point methods above are not likely to be artefacts resulting from hidden persistence.

The potential issue of cross-correlation was also investigated. It was found that less than $9 \%$ of all possible pairings of rainfall data sets display a significant (yet weak) correlation at the $5 \%$ level $(r>0.2$, significance based on $n=100$ ). Only eight pairings (out of 4465 ) were correlated at 0.5 or higher. It was also found that stations located more than $500 \mathrm{~km}$ apart were unlikely to be correlated and that the strength of the correlation decreased as distance increased between the pairs. This is not surprising given annual maximum rainfall events are due to synoptic-scale processes. Therefore, observations relating to spatial consistency of regime shifts are unlikely to be due to spatial correlation between sites.

\subsection{IFD Calculation}

The standard process for obtaining IFD information for a location is to refer to the six master charts of rainfall intensity for various durations and ARIs covering all of Australia in Volume 2 of $A R R$ 2001. Alternatively, IFD curves can be obtained for any location in Australia via the BoM website (both the ARR 1987 and revised IFDs are available). This information is based on regionalized estimates of IFDs that are spatially and temporally consistent. However, this approach cannot be adopted when using the instrumental rainfall data required for the analysis presented in this study. As such, the IFD information generated for this project follows the methodology on which the IFDs were based for ARR 1999 (note the 1987 edition was republished in book form in 1999 with only the chapter on the estimation of extreme to large floods updated), which utilizes point source data with no regionalization. It should be noted that it is not the purpose of this paper to compare different methods of generating IFDs, rather, one method has been adopted in order to provide a comparative assessment of the impact of non-stationarity on IFD estimation. The ARR 1999 procedure used to generate IFDs from raw rainfall data (i.e. point based estimates) is summarised as follows.

- A log-Pearson III distribution was fitted to the annual maxima time series using the method of moments (for annual maxima series of $30 \mathrm{~min}-72 \mathrm{~h}$ duration). This is the standard distribution that has historically been adopted for generating IFDs in Australia; however, other distributions have recently been tested as part of the revision of $A R R$. To test if this distribution is suitable for the region being studied, the goodness of fit for the log-Pearson III was tested using a KolmogorovSmirnov (KS) test. Here the null hypothesis is that the data fits the log-Pearson III distribution (the alternative is that the data does not follow the log-Pearson III distribution). All $p$ values were greater than 0.05 (average $p$ value was 0.75 ) for all series $(30 \mathrm{~min}-72 \mathrm{~h}$ durations 
at Brisbane, Sydney, and Melbourne); therefore, we accept the null hypothesis at the $5 \%$ significance level.

- The coefficient of skewness was determined for each duration $(30 \mathrm{~min}-72 \mathrm{~h})$.

- The coefficient of skewness was then used to obtain a frequency factor, $\mathrm{K}_{Y}$, for use with log-Pearson III distribution. $\mathrm{K}_{Y}$ was obtained from Table 2.2 (positive skew coefficients) and Table 2.3 (negative skew coefficients) in ARR 1999 Book 4.

- Rainfall intensities for a range of ARI were calculated using the following formula:

$\log \mathrm{RI}_{Y}=M+K_{Y} S$.

Where $\mathrm{RI}_{Y}$ is the rainfall intensity having an ARI of 1 in $Y ; M$ is the mean of the logarithms of the annual maximum rainfalls; $S$ is the standard deviation of the logarithms of the annual maximum rainfalls; and $K_{Y}$ is the frequency factor for the required ARI of 1 in $Y$.

- ARIs of 2-10 years were adjusted to partial-duration series estimates. In ARR 1999, the following correction factors were used (note: for ARI greater than 10 years, no corrected factor is required): 2-year ARI - 1.13, 5year ARI - 1.04, 10-year ARI - 1.0.

It should be noted that this approach is likely to result in different estimates of IFDs than those obtained from the standard maps provided by ARR 1999 or the revised IFD estimates released in 2013. Here we are using point-based rainfall data, whereas ARR 1999 derived regionalized estimates based on multiple rainfall stations with varying lengths of data, varying resolution (daily and pluviograph), and varying quality of records. It is recognized that analysis of rainfall data from single stations is often unreliable, is not temporally or spatially consistent, and should generally not be used for design purposes. However, the use of point-based rainfall data satisfies the specific aims of this study (which is a comparative analysis) and is therefore considered appropriate.

\section{Results}

\subsection{Test for regime shifts in the annual maximum rainfall time series}

Significant step changes identified in the extreme rainfall time series are shown in Fig. 2. Of the 66 sub-daily rainfall stations tested, $40(61 \%)$ displayed at least one step change in the $1 \mathrm{~h}$ annual maxima time series (Fig. 2a), with some stations exhibiting multiple shifts. Of the 96 daily rainfall stations tested, 86 displayed at least one step change in the 1-day annual maxima time series (Fig. 2b), while 92 exhibited at least one shift in the 7-day annual maxima time series (Fig. 2c), and some stations exhibited multiple shifts.

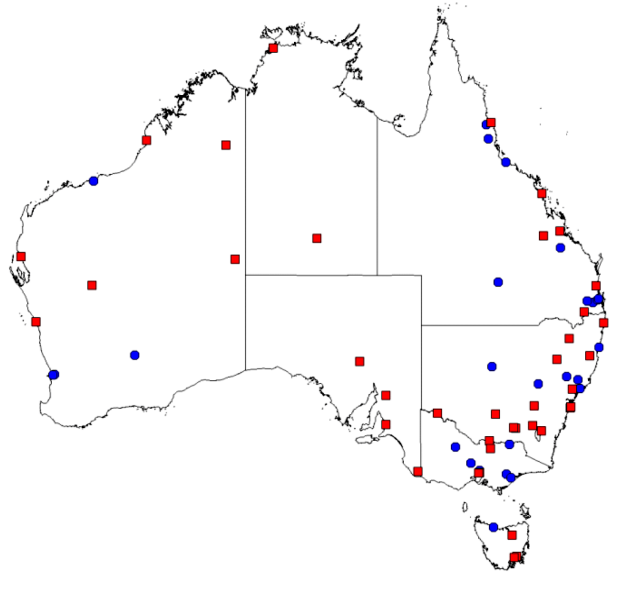

(a)

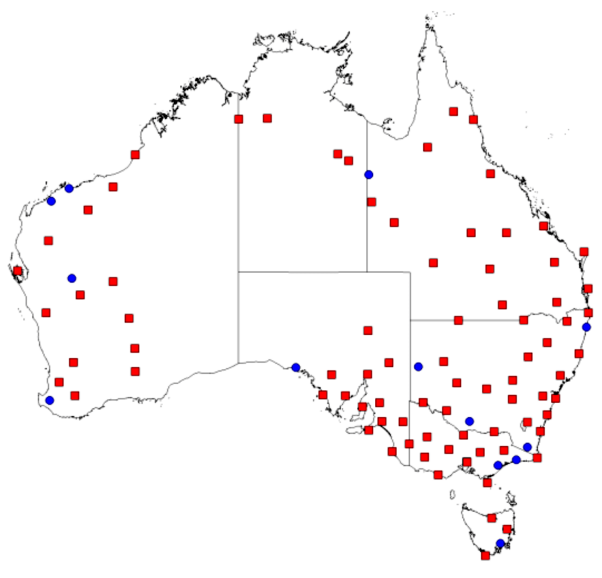

(b)

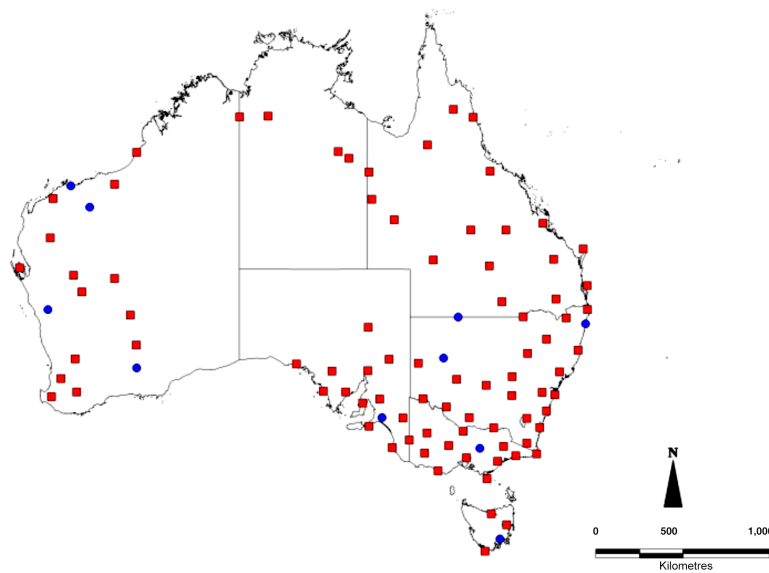

Figure 2. Stations (in red) with at least one statistically significant step change in the (a) $1 \mathrm{~h}$, (b) 1-day, and (c) 7-day annual maximum rainfall (using the Mann-Whitney $U$ test).

Figure 2 collectively shows that observed step changes (or regime shifts) in annual maximum rainfall are not confined to any one particular region of Australia, with most stations analysed exhibiting at least one statistically significant shift. 
(a)

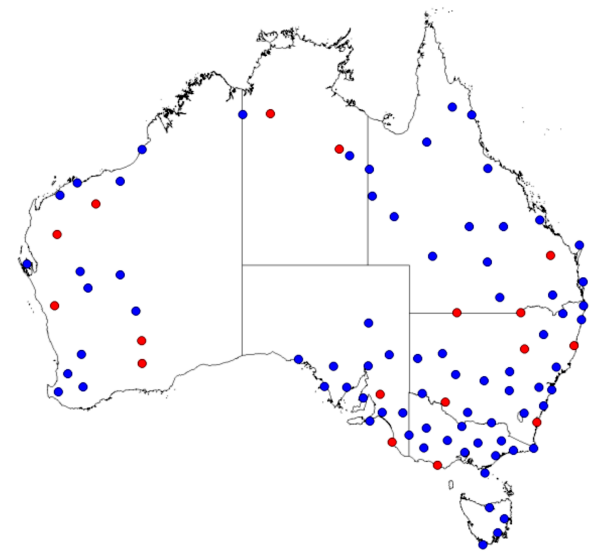

(b)

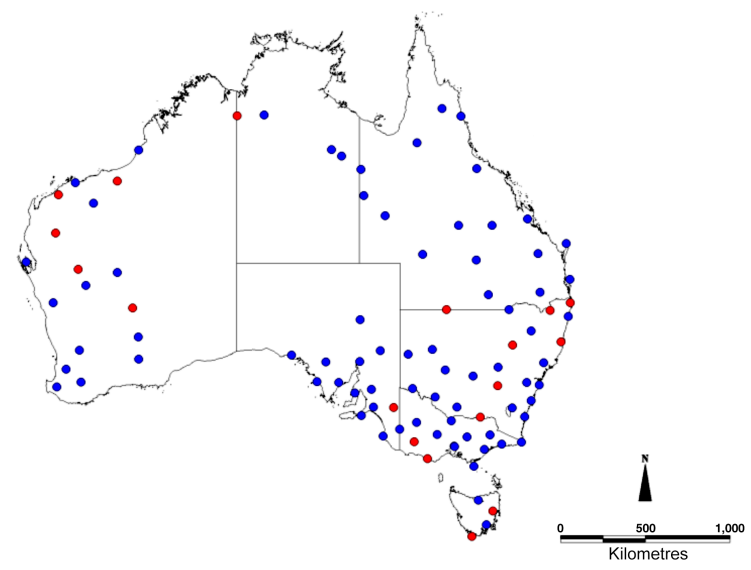

Figure 3. Stations (in red) with at least one statistically significant step change in (a) the 1-day and (b) 7-day annual maximum rainfall (using the CUSUM test with resampling).

As shown in Fig. 3, the CUSUM test yielded fewer stations with statistically significant step change in the annual maxima time series (only 18 stations out of 96) and many of these were clustered along the coastal fringe of eastern Australia (note that, although the total number of stations displaying significant change points was the same for both the 1-day and 7-day annual maxima, in some cases the location of the stations differed between the two). However, as stated previously a limitation to this method is that only one significant change can be detected using the CUSUM test (given that the data is sequentially split into two portions during testing). This can be a problem if more than one step change or cycle in the data is present (see example time series in Fig. 4). Therefore, while the number of stations displaying a step change is reduced using the alternative method, the results do in fact support the theory that regime shift(s) in the annual time series are present for some stations at different durations.

The temporal consistency of step changes in the annual maxima time series was further investigated (Fig. 5a) and it

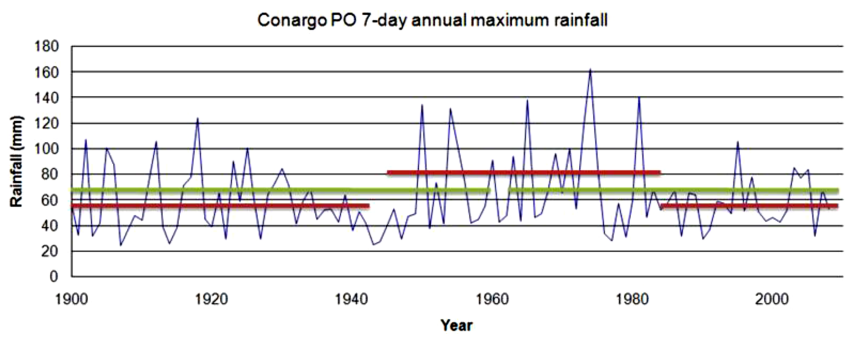

Figure 4. Example of inadequate identification of non-stationarity using the CUSUM test (red line highlights three distinct epochs of high/low rainfall, while green line demonstrates effect of splitting the data into two sections for the CUSUM test).

was found that the timing of observed shifts was not necessarily consistent across Australia. However, for some regions (e.g. the east coast of Australia) periods such as the 1940s (Fig. 5b) and to a lesser degree the 1970s (Fig. 5c) display a higher degree of spatial consistency.

Instability and storminess can result during periods when a number of climate driving mechanisms interact (e.g. El Niño-Southern Oscillation, Indian Ocean Dipole and the Southern Annular Mode) to influence the occurrence of regional weather systems such as east coast lows and cut-off lows (Pook et al., 2006; Verdon-Kidd and Kiem, 2009). However, the large-scale climate phenomena impact various regions of Australia at different times of the year and to varying degrees; therefore, it is not surprising that the timing of shifts in the annual maxima time series varies spatially and temporally. This highlights the limitations of trying to assess and attribute variability in annual maximum rainfall based on a single climate driver (e.g. ENSO) or attempting to address the issue of climate trends for the whole of Australia using one simple approach or model.

\subsection{Effect of non-stationarity on IFD estimation}

Section 3.1 provided evidence of non-stationarity in the annual maxima time series for a range of durations. This nonstationarity may ultimately influence the IFD estimation depending on the length of data and the time period it comes from and therefore the underlying climatic state (or combination of states). Current IFD estimates for Australia (both the 1987 and 2013 versions) are based on data as short as 30 years for the daily read stations and 8 years for the sub-daily data. Therefore, IFD estimates based on relatively short-term data sets may under- or over-estimate rainfall intensities, depending on where the data series fits within the long-term context (i.e. before or after a shift in annual maxima).

For many east coast stations a shift in 1-day annual maxima (along with the 7-day) occurred around the 1940s-1950s and again in the 1970s. This timing also corresponds to wellknown periods of change in the IPO (see Sect. 2.1.2 for a description of the IPO and its influences). Therefore, to fur- 


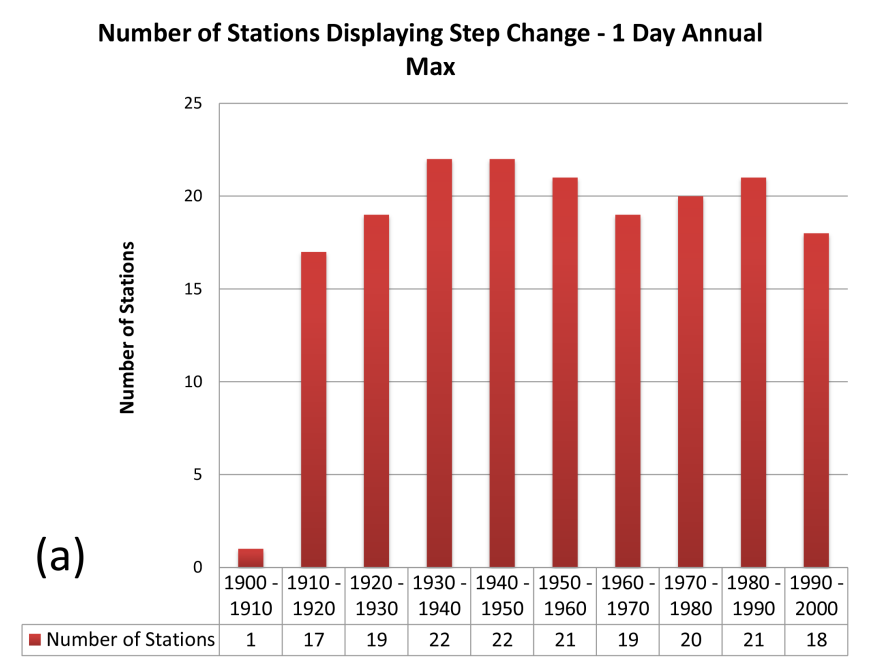

ther explore the issue of regime shifts, breakpoints in the IPO were used to stratify the annual maximum rainfall time series into IPO positive and negative epochs for the three long subdaily data sets described in Sect. 2.1.1 (i.e. Brisbane, Sydney, and Melbourne; see Fig. 1a for location). The reason for selection of these stations was twofold. Firstly, for all three stations, a shift in the annual maxima time series (for 1-day and 7-day) was observed during the 1940s and again in the 1970s. Secondly, the stations contain long records of pluviograph data (the shortest being from 1913 onwards). Figure 6a shows the modulating effect of the IPO on total annual rainfall for the three east coast stations. Annual maxima at the three east coast stations during the two IPO epochs are also shown in Fig. 6b-d for event durations of $30 \mathrm{~min}-72 \mathrm{~h}(\mathrm{du}-$ rations that are critical for flood design applications). A twosample KS test was applied to determine if the observed differences between the IPO positive and negative rainfall distributions are statistically significant. Here the null hypothesis is that the two samples are drawn from the same distribution.

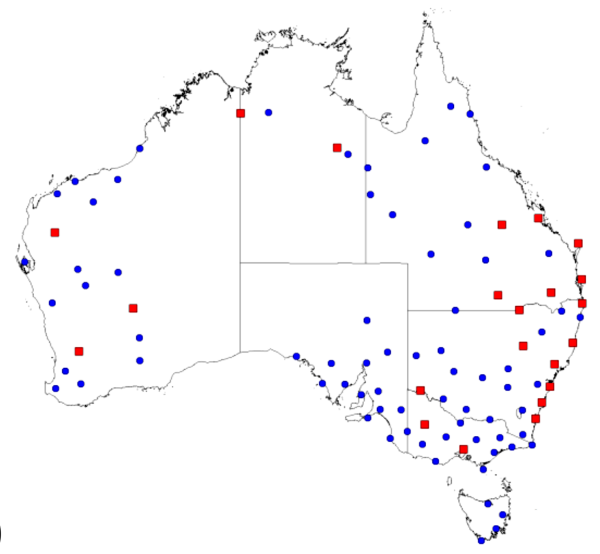

It is evident from Fig. 6a that the effect of the IPO on annual rainfall totals (as measured by the largest difference between the two rainfall distributions associated with each climate phase and the results of the KS test) is greatest for Sydney. Although there does appear to be some impact in Brisbane, the result was not statistically significant according to the KS test. Melbourne does not appear to be greatly influenced by the IPO in terms of annual rainfall variability. This is due to the fact that the southern regions of Australia are affected by other climate modes than those arising from the Pacific (i.e. the Southern Annular Mode and the Indian Ocean Dipole; e.g. Kiem and Verdon-Kidd, 2010; Gallant et al., 2012). Regions such as Brisbane and Sydney tend to be dominated by Pacific Ocean influences (e.g. Verdon et al., 2004). Figure $6 \mathrm{~b}$ shows annual maximum rainfall tends to be higher during negative IPO, on average, for durations of $6 \mathrm{~h}$ and longer at Brisbane (though not statistically significant according to the KS test), while Fig. 6c confirms the same to be true for Sydney for durations of $2 \mathrm{~h}$ and longer (statistically significant at $95 \%$ ). However, for Sydney, the outliers (represented by circles) tend to be larger during positive IPO, indicating that the less frequent events might be more intense during this phase.

Irrespective of the fact that the annual rainfall totals for Melbourne do not show any significant difference between the two phases of the IPO, there does appear to be a consistent relationship between IPO and the sub-daily and daily statistics (Fig. 6d), whereby the median of the positive IPO distribution is higher across all durations; however, negative IPO is associated with less frequent but more extreme events (although results were not statistically significant based on the KS test). For events lasting $24 \mathrm{~h}$ and longer, the negative IPO distribution also shows a much higher degree of variability than for shorter durations, with the "box and whiskers" extending beyond the positive IPO counterpart for these longer durations. This suggests that while IPO might 

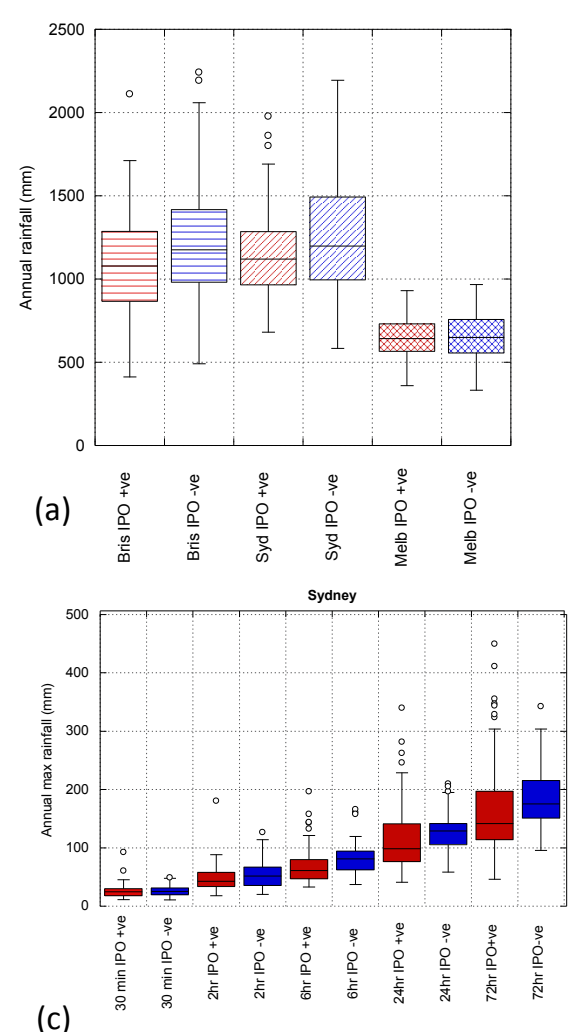

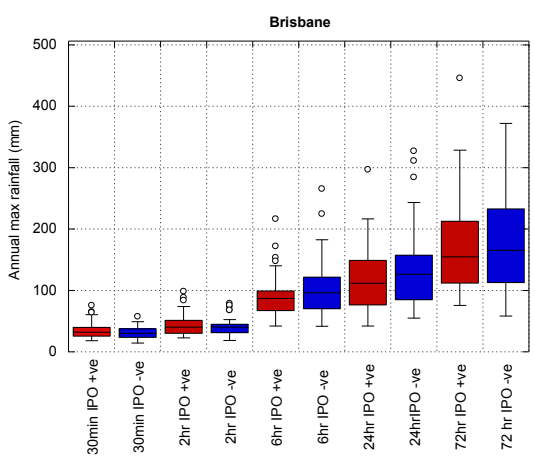

(b)

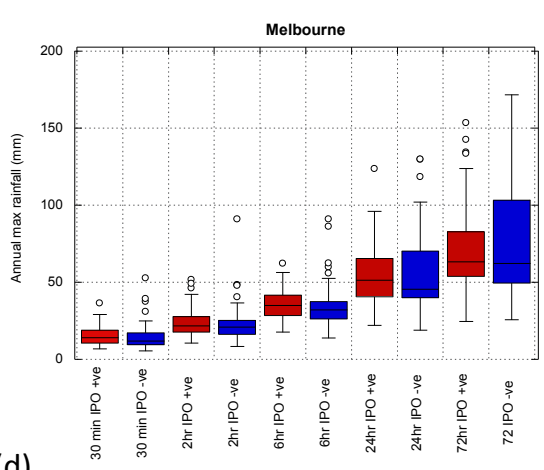

(d)

Figure 6. Relationship between IPO and (a) total annual rainfall, and annual maximum rainfall at various durations for (b) Brisbane, (c) Sydney, and (d) Melbourne.

not be as dominant in southeastern Australia as it is further to the north, it still has some influence that needs to be better understood.

Based on the analysis presented in Fig. 6 and the results of the KS test, the Sydney record was chosen to further investigate the effects of regime shifts on IFD estimation. IFD information was generated for the Sydney record using rainfall data from the two IPO phases and the methodology outlined in Sect. 2.1 for durations from $6 \mathrm{~min}$ through to $72 \mathrm{~h}$ and ARI of 2-200 years. In order to test the robustness of the point estimates of rainfall return levels and estimate the uncertainty in their calculation, a simple bootstrap procedure was carried out. Firstly, the IPO positive and IPO negative rainfall time series were resampled with replacements to obtain two new B samples. Then, for each B sample the log-Pearson III distribution was fitted and the rainfall intensities calculated for the various return intervals. The difference between the rainfall intensities (of the two B samples) was then calculated. This procedure was repeated 100 times to build the empirical distribution of the differences (which represents the effects of sampling and parameter estimation uncertainties under the hypothesis of the existence of two different regimes).

Figure 7 shows the difference in rainfall intensity between IPO positive and IPO negative estimates, along with the $95 \%$ confidence intervals (CIs) derived using the procedure above.
Figure 7 demonstrates clear differences in the resulting rainfall intensities for Sydney estimated for each duration and ARI using the two regimes (i.e. rainfall data from either negative or positive IPO). The difference in rainfall intensity estimated is as great as $65 \%$ in some cases. In all cases, the magnitude of the difference in rainfall intensity estimated using the different data regimes is greater for less frequent events (e.g. 50-, 100-, and 200-year ARIs), highlighting that uncertainty is greatest with less frequent events. The rainfall intensity is greater in positive IPO for the very short duration events $(6 \mathrm{~min})$ at all return intervals and for $30 \mathrm{~min} \mathrm{du}-$ ration events for return intervals of 10 years or more. Similarly, for the 24 and $72 \mathrm{~h}$ duration events rainfall intensity in the positive IPO phase is higher for return intervals of 5 years or more. For 2 and $6 \mathrm{~h}$ events, the negative phase results in higher intensity events for more frequent return levels (20 years or less) but lower intensities for less frequent events (50 years or more).

\section{Discussion and conclusions}

An analysis of regime shifts in the annual maxima time series ( $1 \mathrm{~h}, 1$-day, and 7-day) has been carried out using a set of high quality daily and sub-daily rainfall stations across Australia. It was found that the annual maxima time series does 

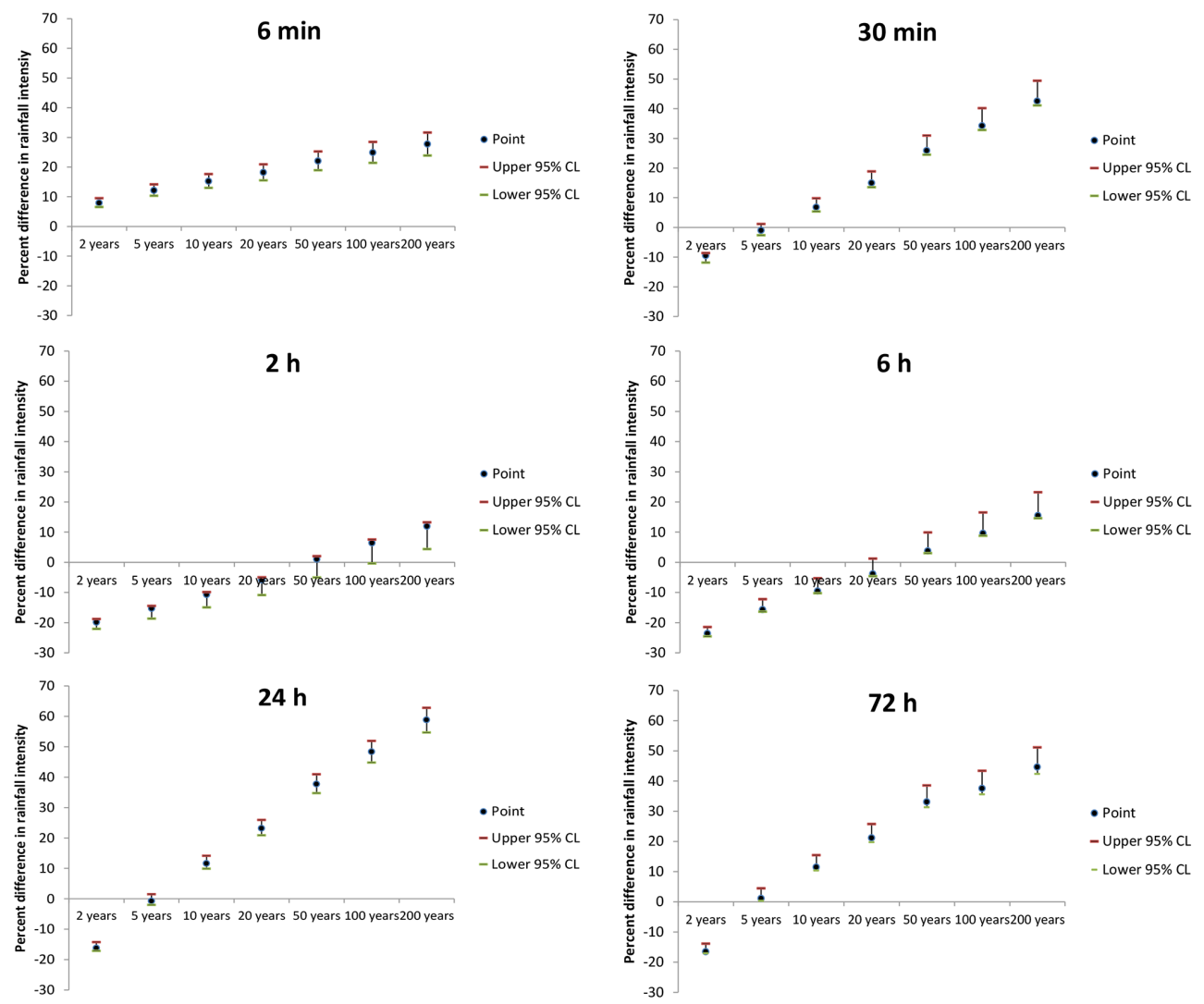

Figure 7. Difference in rainfall intensity for each duration and ARI (for Sydney). Positive (negative) values represent an increase (decrease) in rainfall intensity during positive IPO compared to negative IPO.

indeed exhibit statistically significant step changes/shifts for the majority of stations and for various durations. Furthermore, it was demonstrated using three long-term sub-daily rainfall stations along the east coast that this impacts the resulting IFD estimation. The potential for ocean-atmospheric processes (i.e. the IPO) to affect the resulting IFD estimation was explored in order to demonstrate this issue. The authors acknowledge that the IPO is unlikely to be the only driver of variability in the annual maxima time series across Australia, and it is recommended that future research should aim to identify other potential drivers of this variability.

These findings highlight the fact that in some instances the IFD estimates currently being used are likely to be either under- or overestimated at any one time depending on the length of data and climatic state from which they were derived. This is a particular concern given that current regionalized IFD information is based on data of varying length (as short as 8 years in the case of sub-daily data) spanning different time periods. An overestimation of rainfall intensity for a given duration could impact construction costs, while the risks of underestimating rainfall intensities could result in failure of design criteria. That is, the risk is dependent on the application and length of time over which the risk is assessed.
Further revisions of $A R R$ are currently underway to include an assessment of the potential impacts of climate change on IFD estimates. However, there are many uncertainties associated with climate change projections, particularly when extracting information on timescales shorter than a season and for hydrological extremes (e.g. Blöschl and Montanari, 2010; Kiem and Verdon-Kidd, 2011; Koutsoyiannis et al., 2008, 2009; Montanari et al., 2010; Randall et al., 2007; Stainforth et al., 2007; Stephens et al., 2012; VerdonKidd and Kiem, 2010). Therefore, assessing future changes in extreme events that occur over short durations (e.g. minutes to days) is inherently difficult. Furthermore, climate projections are often presented in terms of a percent change from a particular baseline. However, the baseline is often inconsistent and ill-defined, leading to very different estimates of risk depending on the time over which the baseline is calculated (as has been demonstrated in this paper). Importantly, for regions where large-scale climate drivers operate on a multiyear to multidecadal timescale and are known to influence extreme rainfall events, we can use this information to determine if the climate statistics on which the IFD are based are likely to be biased or missing crucial information.

It is recommended that regime shifts in annual maximum rainfall be considered and appropriately treated in any further 
updates of $A R R$. One way to do this may be to only utilise data sets of similar length, ensuring that they span a sufficient number of years in order to capture data from epochs of both high or low annual maxima (to remove bias towards one climatic phase or another). However, it is acknowledged that this would potentially result in discarding a large amount of data. Alternatively, a separate set of IFDs could be developed for use in high risk modelling for engineers who need to account for the "worst case" (in a similar manner to climate change allowances). This second set of IFDs could be developed based on the periods of elevated annual maxima alone (for those stations with clearly defined epochs of annual maxima) such that, if we were to enter such an epoch, designs based on these estimates would be robust for the duration of such a period. Salas and Obeysekera (2014) provide similar recommendations to deal with changing exceedance probabilities over time. This would have to be assessed and calculated on a region by region basis given that Australia is a country associated with high spatial and temporal rainfall variability caused by numerous large-scale climate drivers and regional weather phenomena. Finally, any revised estimates of annual maxima should be compared in terms of uncertainty bounds (e.g. following Koutsoyiannis, 2006). An uncertainty analysis which takes into account both the data availability and variability within the observation period would provide relevant information to practitioners about the reliability of IFD estimates.

This study has highlighted the existence of regime shifts in annual maximum rainfall data in Australia. The driving mechanisms of these regime shifts are likely to vary from location to location and decade to decade. However, these shifts are typical of many natural phenomena and can be described by processes characterized by long-range dependence (or regime-switching processes) and captured by hidden Markov models (or similar), resulting in a mixture of distributions that alternate stochastically according to the transition probability from one regime to the next (e.g. Serinaldi and Kilsby, 2015a). While the strategy of defining IFDs for two (or more) different regimes (e.g Serinaldi and Kilsby, 2015a) currently only partially solves the problem, as we often do not know the beginning or the end of a specific regime (be it rainfall or climate driver), recent work has focused on optimizing designs and planning strategies based on the range of what is plausible rather than a reliance on knowing the current and future climate state (e.g. Mortazavi-Naeini et al., 2015). At the same time, work is also underway on seamless prediction at a range of timescales and if/when this eventuates the results discussed here become even more important/useful. Nevertheless, the immediate usefulness of the insights presented here occurs when first establishing the IFD, as an approach similar to that employed here can be used to determine if the underlying data are biased to a mostly wet or mostly dry regime (or a mix of both) which then provides an indication as to whether the IFD is likely to be an over- or underestimate of the true risk. Importantly, this issue needs to be considered and accounted for when attempting to estimate IFD design rainfalls and prior to quantifying how those IFD estimates might change in both the near- and long-term future.

While the analysis presented here has been conducted using rainfall data from Australia alone, the recommendations provided are likely to be applicable for other regions of the world where IFD information is based on short-term records and particularly for locations with a highly variable climate.

Acknowledgements. The authors wish to acknowledge the Australian BoM for supplying the rainfall data used in this study and the UK Meteorological Office for kindly making the IPO data available. We would also like to thank Andrew Magee for assisting with statistical analysis of the rainfall data and the two reviewers of the paper, who provided feedback that greatly improved the paper.

Edited by: N. Ursino

\section{References}

Bara, M., Gaal, L., Kohnova, S., Szolgay, J., and Hlavcova, K.: Estimation of IDF curves of extreme rainfall by simple scaling in Slovakia, Contributions to Geophysics and Geodesy, 39, 187206, 2009.

Bernard, M. M.: Formulas for rainfall intensities of long duration, Trans. ASCE, 96, 592-624, 1932.

Blöschl, G. and Montanari, A.: Climate change impacts - throwing the dice?, Hydrol. Proc., 24, 374-381, doi:10.1002/hyp.7574, 2010.

Chen, C. L.: Rainfall intensity-duration-frequency formulas, ASCE J. Hydraul. Eng., 109, 1603-1621, 1983.

Douglas, E. M., Vogel, R. M., and Kroll, C. N.: Trends in floods and low flows in the United States: impact of spatial correlation, J. Hydrol., 240, 90-105, 2000.

Durbin, J. and Watson, G. S.: Testing for Serial Correlation in Least Squares Regression, I, Biometrika, 37, 409-428, doi:10.1093/biomet/37.3-4.409, 1950.

Durbin, J. and Watson, G. S.: Testing for Serial Correlation in Least Squares Regression, II, Biometrika, 38, 159-179, doi:10.1093/biomet/38.1-2.159, 1951.

Erskine, W. D. and Warner, R. F.: Geomorphic effects of alternating flood and drought dominated regimes on a coastal NSW river, in: Fluvial Geomorphology of Australia, Academic Press, Sydney, Australia, 223-244, 1988.

Folland, C. K., Parker, D. E., Colman, A. W., and Washington, R.: Large scale modes of ocean surface temperature since the late nineteenth century, in: Beyond El Nino: Decadal and Interdecadal Climate Variability, Springer, Berlin, 73-102, 1999.

Franks, S. W. and Kuczera, G.: Flood frequency analysis: Evidence and implications of secular climate variability, New South Wales, Water Resour. Res., 38, 1062, doi:10.1029/2001WR000232, 2002.

Gallant, A. J. E., Kiem, A. S., Verdon-Kidd, D. C., Stone, R. C., and Karoly, D. J.: Understanding hydroclimate processes in the Murray-Darling Basin for natural resources management, Hy- 
drol. Earth Syst. Sci., 16, 2049-2068, doi:10.5194/hess-16-20492012, 2012.

Guerreiro, S. B., Kilsby, C. G., and Serinaldi, F.: Analysis of time variation of rainfall in transnational basins in Iberia: abrupt changes or trends?, Int. J. Climatol., 34, 114-133, 2014.

Hershfield, D. M.: Rainfall Frequency atlas of the United States for durations from 30 minutes to 24 hours and return period s from 1 to 100 years, tech. paper 40, US Department of Comm., Weather Bureau, Washington, D.C., 1961.

IHP-VII (International Hydrological Programme): Technical Documents in Hydrology - No. 2, Asian Pacific FRIEND, Rainfall Intensity Duration Frequency (IDF), Analysis for the Asia Pacific Region, edited by: Daniell, T. M. and Tabios III, G. Q., Reported by Regional Steering Committee for Southeast Asia and the Pacific, UNESCO Office, Jakarta 2008, 2008.

Ishak, E. H., Rahman, A., Westra, S., Sharma, A., and Kuczera, G.: Evaluating the non-stationarity of Australian annual maximum flood, J. Hydrol., 494, 134-145, 2013.

Jakob, D., Karoly, D. J., and Seed, A.: Non-stationarity in daily and sub-daily intense rainfall - Part 1: Sydney, Australia, Nat. Hazards Earth Syst. Sci., 11, 2263-2271, doi:10.5194/nhess-112263-2011, 2011a.

Jakob, D., Karoly, D. J., and Seed, A.: Non-stationarity in daily and sub-daily intense rainfall - Part 2: Regional assessment for sites in south-east Australia, Nat. Hazards Earth Syst. Sci., 11, 22732284, doi:10.5194/nhess-11-2273-2011, $2011 \mathrm{~b}$.

Khaliq, M. N., Ouarda, T. B. M. J., Ondo, J.-C., Gachon, P., and Bobee, B.: Frequency analysis of a sequence of dependent and/or non-stationary hydro-meteorological observations: A review, J. Hydrol., 329, 534-552, 2006.

Kiem, A. S. and Franks, S. W.: Multi-decadal variability of drought risk - Eastern Australia, Hydrol. Process., 18, 2039-2050, 2004.

Kiem, A. S. and Verdon-Kidd, D. C.: Climatic drivers of Victorian streamflow: Is ENSO the dominant influence?, Austr. J. Water Resour., 13, 17-29, 2009.

Kiem, A. S. and Verdon-Kidd, D. C.: Towards understanding hydroclimatic change in Victoria, Australia - preliminary insights into the "Big Dry", Hydrol. Earth Syst. Sci., 14, 433-445, doi:10.5194/hess-14-433-2010, 2010.

Kiem, A. S., Franks, S. W., and Kuczera, G.: Multi-decadal variability of flood risk, Geophys. Res. Lett., 30, 1035, doi:10.1029/2002GL015992, 2003.

Kiem, A. S. and Verdon-Kidd, D. C.: Steps towards 'useful' hydroclimatic scenarios for water resource management in the Murray-Darling Basin, Water Resour. Res., 47, W00G06, doi:10.1029/2010WR009803, 2011.

Koutsoyiannis, D.: Nonstationarity versus scaling hydrology, J. Hydrol., 324, 239-254, doi:10.1016/j.jhydrol.2005.09.022, 2006.

Koutsoyiannis, D., Efstratiadis, A., Mamassis, N., and Christofides, A.L On the credibility of climate predictions, Hydrol. Sci. J., 53, 671-684, 2008

Koutsoyiannis, D., Montanari, A., Lins, H. F., and Cohn, T. A.: Climate, hydrology and freshwater: towards an interactive incorporation of hydrological experience into climate research - DISCUSSION of "The implications of projected climate change for freshwater resources and their management", Hydrol. Sci. J., 54, 394-405, 2009.
Kundzewicz, Z. W. and Robson, A. J.: Change detection in hydrological records - a review of the methodology, Hydrol. Sci. J., 49, 7-19, 2004.

Leonard, M., Metcalfe, A., and Lambert, M.: Frequency analysis of rainfall and streamflow extremes accounting for seasonal and climatic partitions, Journal of Hydrology, 348, 135-147, 2008.

McKerchar, A. I. and Henderson, R. D.: Shifts in flood and low-flow regimes in New Zealand due to inter-decadal climate variations, Hydrol. Sci. J., 48, 637-654, 2003.

Montanari, A., Blöschl, G., Sivapalan, M., and Savenije, H.: Getting on target, Public Service Review: Science and Technology, 7, 167-169, 2010.

Mortazavi-Naeini, M., Kuczera, G., Kiem, A. S., Cui, L., Henley, B., Berghout, B., and Turner, E.: Robust optimization to secure urban bulk water supply against extreme drought and uncertain climate change, Environ. Model. Softw., 69, 437-451, 2015.

Nhat L., Tachikawa, Y., and Takara, K.: Establishment of IntensityDuration-Frequency Curves for Precipitation in the Monsoon Area of Vietnam, Annuals of Disas. Prev. Res. Inst., Kyoto Univ., No. 49, 2006.

Pilgrim, D. H.: Australian Rainfall \& Runoff - A Guide to Flood Estimation, Institution of Engineers, Australia, Barton, ACT, 1987.

Pook, M. J., McIntosh, P. C., and Meyers, G. A.: The Synoptic Decomposition of Cool-Season Rainfall in the Southeastern Australian Cropping Region, J. Appl. Meteorol. Climatol., 45, 11561170, 2006.

Power, S., Casey, T., Folland, C., Colman, A., and Mehta, V.: Interdecadal modulation of the impact of ENSO on Australia, Clim. Dynam., 15, 319-324, 1999.

Raiford, J. P., Aziz, N. M., Khan, A. A., and Powell, D. N.: Rainfall Depth-Duration-Frequency Relationships for South Carolina, North Carolina, and Georgia, Am. J. Environ. Sci., 3, 7884, 2007.

Randall, D. A., Wood, R. A., Bony, S., Colman, R., Fichefet, T., Fyfe, J., Kattsov, V., Pitman, A., Shukla, J., Srinivasan, J., Stouffer, R. J., Sumi, A., and Taylor, K. E.: Climate Models and Their Evaluation, in: Climate Change 2007: The Physical Science Basis. Contribution of Working Group I to the Fourth Assessment Report of the Intergovernmental Panel on Climate Change, edited by: Solomon, S., Qin, D., Manning, M., Chen, Z., Marquis, M., Averyt, K. B., Tignor, M. and Miller, H. L., Climate Models and Their Evaluation, Cambridge University Press, Cambridge, UK and New York, USA, 2007.

Salas, J. D. and Obeysekera, J.: Revisiting the concepts of return period and risk for nonstationary hydrologic extreme events, J. Hydrol. Eng., 19, 554-568, 2014.

Serinaldi, F. and Kilsby, C. G.: Stationarity is undead: Uncertainty dominates the distribution of extremes, Adv. Water Resour., 77, 17-36, 2015a.

Serinaldi, F. and Kilsby, C. G.: The importance of prewhitening in change point analysis under persistence, Stoch. Environ. Res. Risk Assess., doi:10.1007/s00477-015-1041-5, 2015b.

Stainforth, D. A., Allen, M. R., Tredger, E. R., and Smith, L. A.: Confidence, uncertainty and decision-support relevance in climate predictions, Phil. Trans. Roy. Soc., 365, 2145-2161, doi:10.1098/rsta.2007.2074, 2007.

Stephens, E. M., Edwards, T. L., and Demeritt, D.: Communicating probabilistic information from climate model ensembles 
- lessons from numerical weather prediction, WIREs Clim. Change, 2012, 409-426, doi:10.1002/wcc.187, 2012.

Verdon, D. C. and Franks, S. W.: Long-term behaviour of ENSO: Interactions with the PDO over the past 400 years inferred from paleoclimate records, Geophys. Res. Lett., 33, L06712, doi:10.1029/2005GL025052, 2006.

Verdon-Kidd, D. C. and Kiem, A. S.: On the relationship between large-scale climate modes and regional synoptic patterns that drive Victorian rainfall, Hydrol. Earth Syst. Sci., 13, 467-479, doi:10.5194/hess-13-467-2009, 2009.

Verdon-Kidd, D. C. and Kiem, A. S.: Quantifying drought risk in a non-stationary climate, J. Hydrometeorol., 11, 1019-1031, 2010.

Verdon, D. C., Wyatt, A. M., Kiem, A. S., and Franks, S. W.: Multidecadal variability of rainfall and streamflow - Eastern Australia, Water Resour. Res., 40, W10201, doi:10.1029/12004WR003234, 2004.
Wang, B. and An, S.-I.: Why the properties of El Nino changed during the late 1970s, Geophys. Res. Lett., 28, 3709-3712, doi:10.1029/2001GL012862, 2001.

Westra, S. and Sisson, S. A.: Detection of non-stationarity in precipitation extremes using a max-stable process model, J. Hydrol., 406, 119-128, 2011.

Yilmaz, A. G., Hossain, I., and Perera, B. J. C.: Effect of climate change and variability on extreme rainfall intensityfrequency-duration relationships: a case study of Melbourne, Hydrol. Earth Syst. Sci., 18, 4065-4076, doi:10.5194/hess-184065-2014, 2014.

Yilmaz, A. and Perera, B.: Extreme Rainfall Nonstationarity Investigation and Intensity-Frequency-Duration Relationship, J. Hydrol. Eng., 19, 1160-1172, doi:10.1061/(ASCE)HE.19435584.0000878, 2014.

Yue, S., Pilon, P., and Phinney, B.: Canadian streamflow trend detection: impacts of serial and cross-correlation, Hydrol. Sci. J., 48, 51-64, 2003. 